\title{
IS CORPORATE SOCIAL RESPONSIBILITY A MANAGEMENT FASHION IN NORWAY? SOME PRELIMINARY EVIDENCE
}

\author{
Dag Øivind Madsen, Buskerud and Vestfold University College, Hønefoss, Norway \\ Tonny Stenheim, BI Norwegian Business School, Oslo, Norway
}

dx.doi.org/10.18374/EJBR-14-1.7

\begin{abstract}
In recent years Corporate Social Responsibility (CSR) has been the subject of much attention. Commentators have referred to CSR as a â €gTobal movementâ $€$ TMand â €megega-trendâ $€$ TMSome have also suggested that the popularity of the CSR idea resembles that of a typical â €minanagement fashionâ $€$ TMn this article we conduct a preliminary analysis of the evolution and life-cycle of CSR in the Norwegian context. Focusing on the supply-side of CSR, we examine the public discourse around the idea using so-called â Eprint-media indicatorsâ $€$ TMThe discourse data show a rapid growth in the intensity of discourse in the years from 2005 to 2013. Interestingly, the life-cycle curve lags behind that seen in other countries, where CSR-related discourse started several years earlier. This indicates that the take-up of the CSR idea has not been uniform across countries. Based on the findings and a discussion of the limitations of our analysis, we map out a research agenda for studying the take-up and evolution of CSR as a fashionable management idea in different contexts.
\end{abstract}

Keywords: Corporate Social Responsibility, management idea, management concept, management fashion, business media, print-media indicators, discourse 